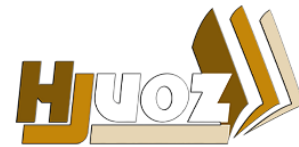

hjuoz.uoz.edu.krd p-ISSN: 2410-7557
كَّوارا زانستيّن مروّقايهتى يا زانكوّيا زاخوّ

مجلة العلوم الانسانية لجامعة زاخو

Humanities Journal of University of Zakho (HJUOZ)

Vol. 5, No. 2, pp. 353-360, June-2017

\title{
جسر زاخو الأثري في المصنفات العربية والغربية
}

نزار علوان عبدالله

قسم التاريخ، كلية التربية، الجامعة المستنصرية، العراق.

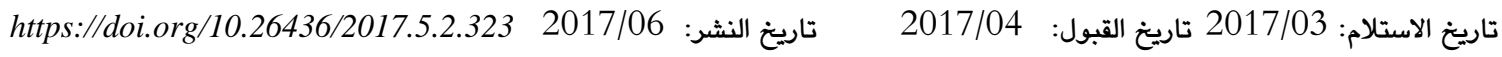

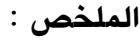

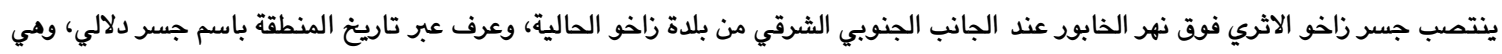
أسطورة رومانية قديمة تدود حول بناء الجسر، لكنه اشتهر عند أهل زاخو بالجسر الحجري الكبير، اما في العهود المعاصرة فقد شاعت تسميته بالجسر العباسي، وهي تسمية حديثة ظهرت بعد تأسيس الدولة العراقية عام 1920 ـ 192

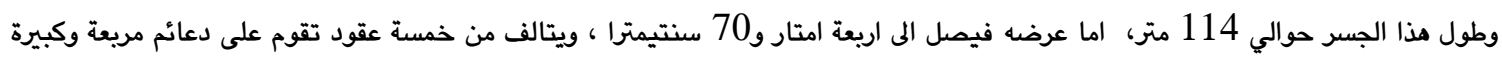

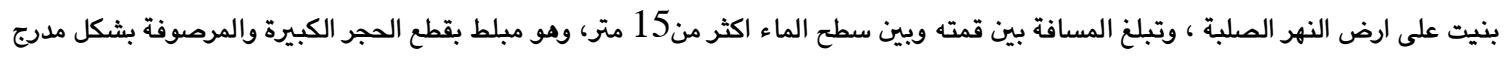

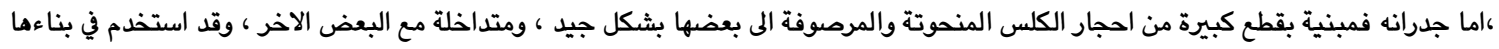

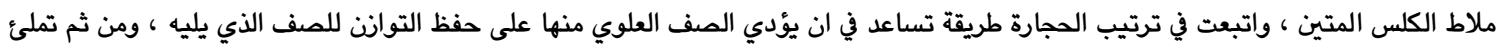
جميع الفراغات الوسطى للجسر بحجر الصوان الصلب مع مادة الكلس والنورة التي لاتتاثر بالرطوبة .

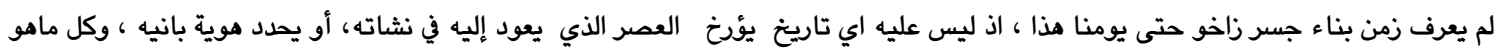

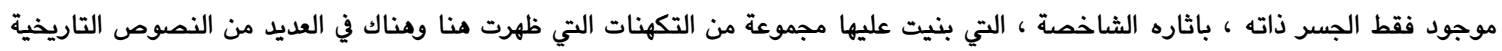

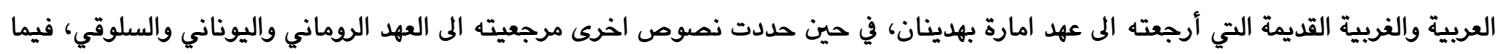

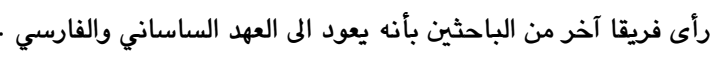
الكلمات الدالة: بلدة زاخو، جسر زاخو، المصنفات العربية و الغربية.

هو، وان كان المقصود مجرد الوقف يحتمل جداً أن يكون جسر

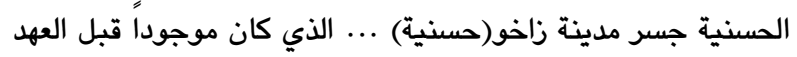

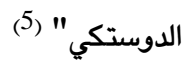
والحسنية هنا هو الاسم القديم لمدينة زاخو، وقد شاعت التسمية في

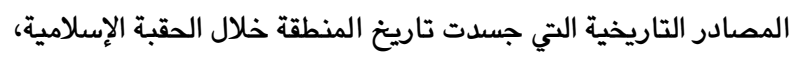
فيقول عنها خضر العباسي: " على نهر الخابور الذي ينبع من جبال حكاري في تركيا، ويصب في نهر دجلة فوق فيشخابور تقع بلدة الحسنية عند مخلج الخابور حول جزيرة زاخو من الجهة الشمالية، وهي بلدة

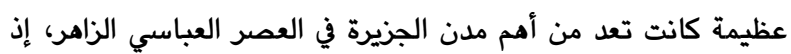
نالت قسطاً من التقدم في العلوم والعمران"(6). وسمي أيضاً جسر الخابور، نسبة الى نهر الخابور الذي قال عنه ياقوت فالقران

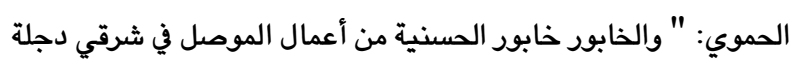
وهو نهر من الجبال عليه عمل واسع وقرى في شمالي الموصل في الجبال له نهر عظيم يسقى عمله ثم يصب في دجلة ومخرجه من أرض النوذان"

\section{1. تسمية الجسر}

يعد جسر زاخو الأثري واحداً من أهم الجسور الدجرية في شمال العراق،

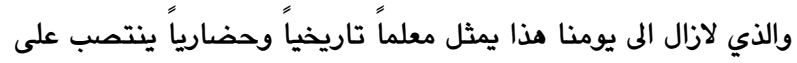

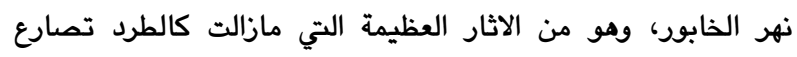

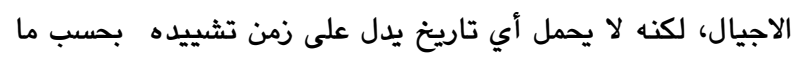

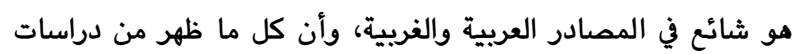
سابقة أرخت لبنائه، فهي مجرد تكهنات لا ترتقي الى مستوى الحقيقة إلا بشيء نسبي. ومع تقادم السنين واختلاف الحقب التاريخية التي مر بها هذا الجسر، ظهرت له تسميات مختلفة، منها قنطرة سنجة كما ورد ذلك في كتاب (

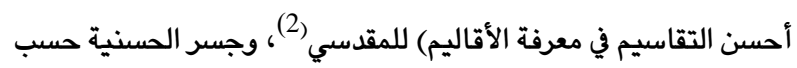

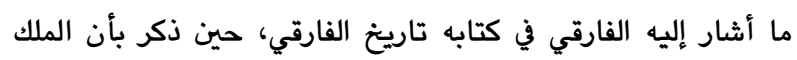

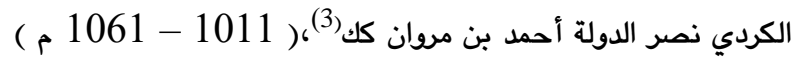
خصص أوقافاً على سبعة جسور ضمن دولته من بينها جسر(الحسنية) (4) . ومذا ما أكده عبد الرقيب يوسف في كتاب الدولة الدوستكية في بئ

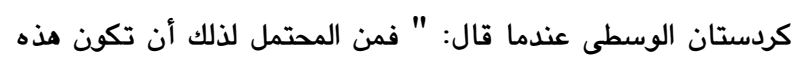
الجسور من انشاء نصر الدولة ، ومن بينها جسر تل بنان الذي شيده 
نستنتج مما سبق بأن هذا الجسر أقيم في بقعه استراتيجية، حيث ممر زاخو الشهير، الأمر الذي يزيد من أهمية الجسر ومكانته التاريخية ـ إذ بـ

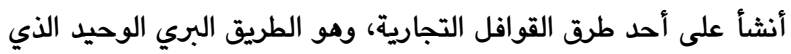
كان يمر بشرقي دجلة ، ويربط بين العراق وبين كل من اقليم ديار بكر

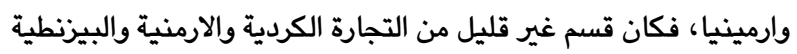
تصل العراق في القرون الوسطى من هذا الطريق، الذي يلتقي عند الموصل بطريق نصيبين، وهو أطول طريق تجاري بري في الشرق آنذاك ، كان يريط بين السواحل الشرقية للبحر الأبيض المتوسط وحتى آسيا

الصغرى، من البلاد الرومانية وحتى العراق وايران والصين(15). ورغم زوال مبررات استخدام الجسر لأغراض تجارية في الوقت الحاضر، لكنه لازال يستخدم لعبور السابلة ، فضلاً عن كونه معلماً تاريخياً

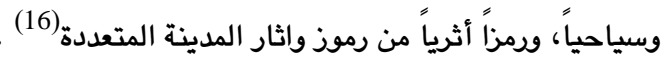

\section{3. صفة الجسر وهيئته}

قد يبدو جسر زاخو للناظر لأول وهله كأنه بسيط التركيب ضعيف القوام ، لكنه بالرغم من مظهره هذا عاش قرونا عديدة ، وتحدى الزمن وفيضانات الخابور المتدفق من اعالي الجبال المحيطة بتلك البقاع ، والتي كانت ذات أمواج متلاطمة ، وهي في صراع دائم مع الصخود

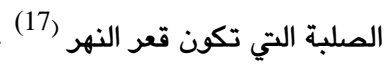
ويعود صمود الجسر لتلك الحقبة الزمنية السحيقة الى اعتماد البنائين في انجازه على أسس صحيحة ، واتباعهم أساليب مندسية وفنية دقيقة

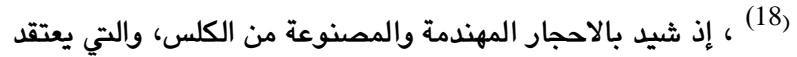
بأنها جلبت من جبل كيري في منطقة شرانش التي تبعد 15 كم من موقع الجسر (19) من جان وتم ربط الأجزاء التي تحتاج الى دقة متناهية لاسيما الأقواس التي تحمل الجسر، باستخدام قضبان حديدية قادرة على حمل وتماسك تلك الاحجار، كما أنهم اتبعوا طريقة ذكية عند ترتيبها بتداخلها مع بعضها ، بحيث يعمل الصف العلوي منها على حفظ التوانن للصف الذي يليه، بعدها يتم ملء جميع الفراغات الوسطى للجسر بحجر الصوان الصلد

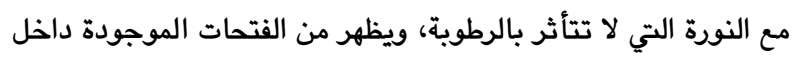
الأقواس انها استخدمت لتثبيت الدعائم الخشبية كمساند لاكمال هذه الأقواس ، وحتى بعمل هيكل خشبي كامل يأخذ شكل القوس الى حيث وضعت الاحجار عليها ، ثم رفع المساند بعد ذلك حال اكمال البناء (20)

اما دعائم الجسر فانها مستقرة فوق قاعدة من الأحجار المربعة

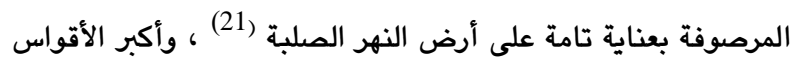
القوس الوسطي الذي يعلو الخابور بكامله إذ تبلغ فتحته 16 متراً (22)

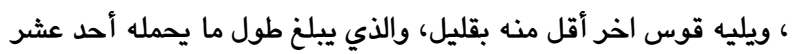
متراً فقط (23) مونيه فوسن
أما التسميات المتداولة محلياً فهي ( برامه نن ) أي الجسر الكبير، و) برامه ري ) أي الجسر الحجري (8) ، لكن الاسم الأكثر شيوعاً وتداولاً في الدراسات القديمة هو جسر دلالي وهو مصطلح يعود في جذوده الى اسطورة رومانية قديمة تدود حول بناء ذلك الجسر، ومفادها بأن محاولات متكررة جرت لتثبيت الجزء الأوسط منه، وفي كل مرة منها كان يسقط ، حتى نفد صبر البنائين وضاقوا ذرعاً بالأمر ، فاضطروات وفئ الاوسط مرة منها الى العمل بنبوءة نصت على ضرورة وضع جسد انسان فوق الحجر الأساس للجسر على أن يكون الضحية أول عابر طريق ، وماهي الإ

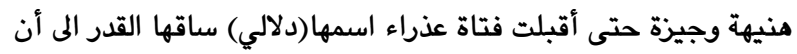
تكون أول من يقع عليها القرار الذي اتخذ من قبل رئيس البنائين لتحقيق تلك النبوءة ، فأدمجت في الحال ببناء الجسر وهي حية، ويهذا

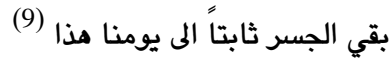
وحال تأسيس الدولة العراقية في العشرينات من القن الماضي، ظهرت تسمية جديدة لجسر زاخو، إذ عرف بالجسر العباسي نسبة الى قرية(عباسي) الواقعة في الجانب الشمالي من الجسر، وهي عبارة عن دور لضباط الصف مع من التحق بهم من سكان المناطق المجاورة ،

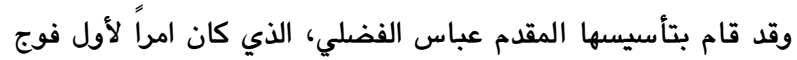

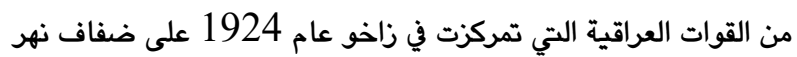
( زي - خابور )، ولاسه سميت تلك القرية(10) .

\section{2. موقع الجسر وأهميته}

ينتصب جسر زاخو الأثري على نحو ميل واحد شرقي بلدة زاخو فوق نهر الخابور الذي ينبع من الجبال الممتدة في جنوبي ارمينيا، ثم يسير بين ثنايا تلك الجبال حتى يصب فوق قرية فيشخابور الواقعة على بعد

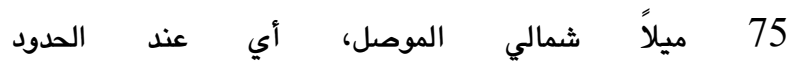
العراقية - التركية(11)

وقد تطرق المستشرق لسترنج الى مذا الموقع في كتابه بلدان الخلافة

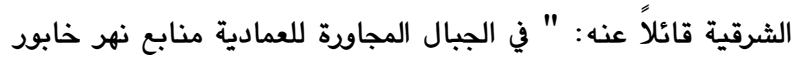
الحسنية وهو يصب في دجلة شمال مدينة فيشخابور على بعد 150

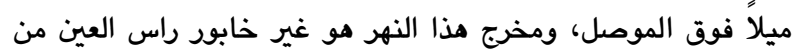
أرض الزوزان ، وعند وصوله الى بلدة الحسنية كان يمر من تحت جسر حجري رائع ماتزال بقاياه قائمة حالياً قرب قرية حسن اغا ... "(12).

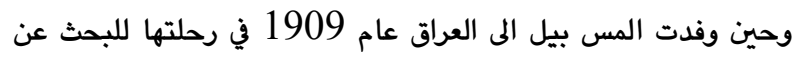
مواطن الاثار في شماله، تحدثت عن الجسر وموقعه، قائلة بأنه ينتصب على الذراع الأيمن من نهر الخابور، بينما تنتصب قلعة زاخو على الذراع

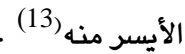
وتناول صاحب كتاب ( From Monte to Mosul ) زاخو وجسرها وهو في طريقه من مونت كارلو الى الموصل حسب ماجاء في النص الآتي : " تقع زاخو على جزيرة في الخابور يربطها جسر بالضفة من مونة اليمنى للنهر ... وهو ذو منظر مميز ومثير للاهتمام " (14) . 
الدولة على الجسر الحسنية والحميدية وتل بنان وقطنيتا ويابوزين

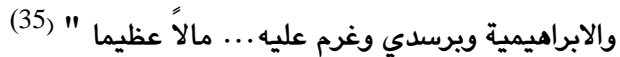
ويفند عبد الرقيب يوسف كلام الفارقي، فيقول أن عبارته تعرضت وبرست للإرباك والخطأ، ولا يدري أن الضمير في ( وغرم عليه) يرجع الى أي من الجسور، ولعل الصحيح (عليها) أي غرم على الجسور المذكور كلها، وأن كان كذلك يكون هو مشيدها، لأن كلمة (غرم عليه) تستعمل عادة لشيء بناه الغريم لا الواقف. كما أن الشخص بصورة عامة يقف هون

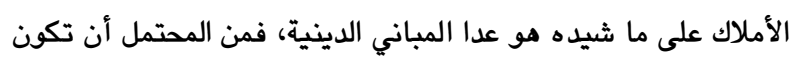
هذه الجسور من إنشاء نصر الدولة، وأن كان المقصود مجرد الوقف ، يحتمل جداً أن يكون جسر الصسنية (جر زاخو) موجود أصلاً قبل الحقبة الدوستكية(36) والى جانب تلك النصوص، هنالك نصوص أخرى أرجعت بناء الجسر الى حقب تاريخية مختلفة، فبعض الكتبة المحثين يرون ان تشييده على الأرجح يعود الى العشرة الاف جندي من المرتزقة الاغريق أثناء

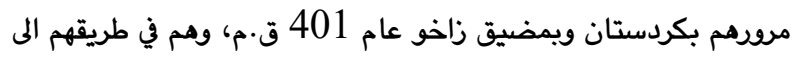
اليونان بقيادة زينوفون ( Xenophon) (37) وهو كلام يعود الى فئل المؤرخ الكردي محمد أمين زكي (38) ، لكن مصدرين آخرين أكثر دقة

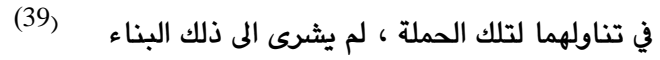
ويذهب اسكيف المفتش في وذارة المعارف العراقية عام 1947 الى ان الجسر يعود في نشأته الى العهد المقدوني السلوقي، الذي خضع العراق

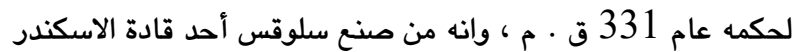
الأكبر (40) .

وترى بعض الدراسات الغربية ان تصميمه وطرازه ( روماني الاصل )

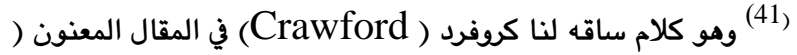
Triumphs of the Roman ) (انتصار بناة الجسور الرومان ) والذي جاء ضمن المقالات التي حررها (Bridge Builders

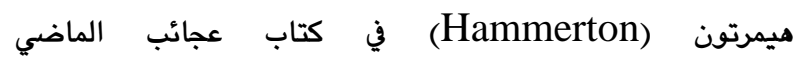

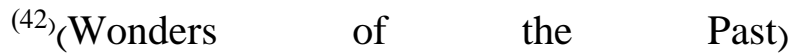
غير ان الدكتور ( Fiey ) يدحض تصورات كروفرد حين يقول بأن هذه القنطرة تعود الى الفترة الاتابكية في الموصل من عصر بدر الدين لؤلؤ، وليست رومانية حسب ما هو شائع حتى الآن (43) ويعتقد عبدالرزاق الحسني بأن الجسر من بقايا العباسيين في العراق

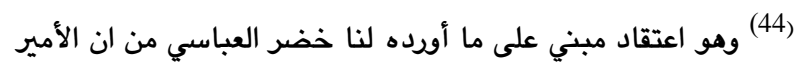
حسن العباسي أمير امارة بهدينان هو الذي أوعز عام 1523 مالى نائبه

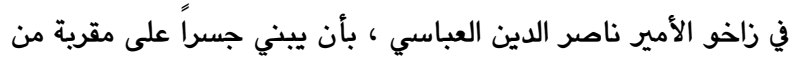
المدينة على ضفاف نهر الخابور ، وذلك لتسهيل مرود جيوش الامارة التي كانت تلاقي عراقيل كثيرة عندما تعبر الى جهة بوتان والشمال،

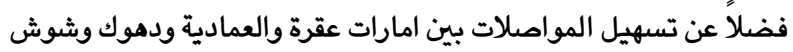
وكندير وغيرها (45)
وعدا القوسين المشار اليهما، هنالك ثلاثة أقواس للجسر لكنها أصغر حجما ، احدهما شيد على يمينه، والاثنان الاخران شيدا على يساره ، ومما يشكلان الممشى الصاعد له من الشاطئ (24) . هذا الوضع والتفاوت في احجام الأقواس حتم ارتفاع وسط الجسر ، ومن

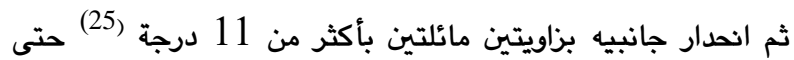
يتساوى وسط الأرض عند حافتي مجرى النهر(26) . وفيما يتعلق بالطول الاجمالي لجسر زاخو ، فيصل الى 60 متراً حسب الارضي الندي

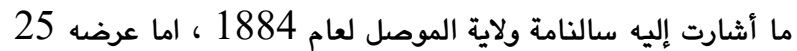
متراً (27) ما آثارت إل

بينما أكد لنا الالماني كونراد برويسر ( ميرا

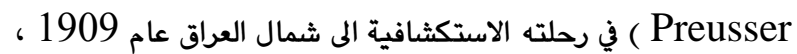

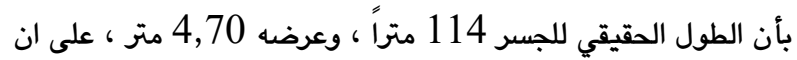
تطرح من ذلك على كل جانب 50 سم للمماشي الجانبية التي يبلغ

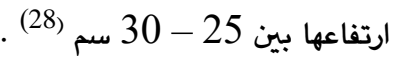

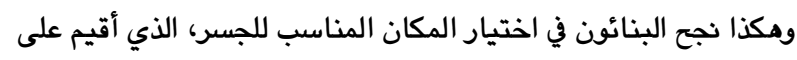

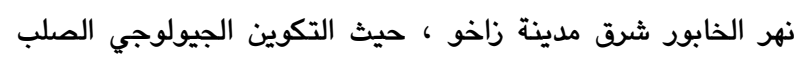
للمكان الذي مكنهم من بناء قاعدة الجسر عليه مباشرة ، والذي يعد مهدي أهم عوامل صموده ويقائه الى يومنا هذا (29) .

4. تباين المصادر واختلافها في تصديد تاريخ بناء الجسر

لم يتفق الاثاريون بعد حتى يومنا هذا على تاريخ بناء جسر زاخو، ولا

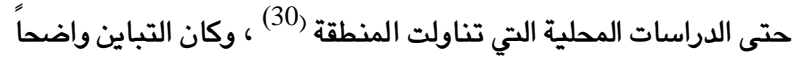
أيضاً بين المؤرخين والرحالة والمستشرقين، لاسيما في كتاباتهم

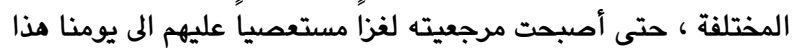

ووجه الاختلاف في ذلك هو افتقار البناء لأي كتابات او علامات دالة

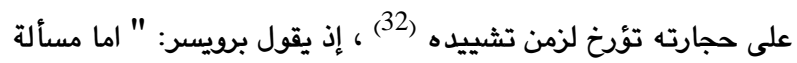
تحديد تاريخ البناء لهذا الجسر فلا يمكن الادلاء برأي معتمد لأنتا لا

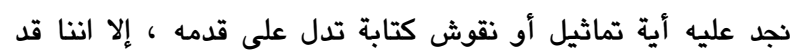

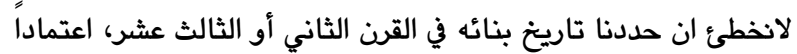
على الانطباع الشامل للجسر " (33) رأي برويسر متقدم بقرنين أو ثلاثة قرون على ما ذكر في كتاب الجغرافي المقدسي الذي انتهى من تأليفه عام 985م والذي تطرق فيه لزاخو وجسرها الشهير، وهو يسميه قنطرة ( سنجة)، مما يعني بأن الجسر

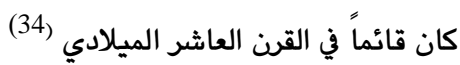
وقد لا نذهب بعيداً حين نعرج على كتاب الفارقي الذي أشار فيه الى

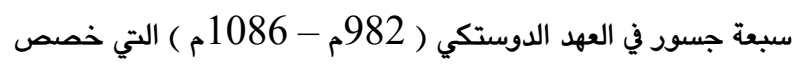
لها الملك نصر الدولة أحمد بن مروان أوقافاً مختلفة ، وكان جسر زاخو المسمى جسر الحسنية من بينها حسب النص الآتي: " ووقف نصر مروان الهاه 
امرأة بجنبه، وصورة طير ( النسر)، كلها على حجر واحد ، مع رسوم الطاووس وئوس الثور والحصان ورسوم ورموز أخرى، وكتابتين بهلويتين على أحجار كثيرة ومتفرقة (53) . ويعتقد عبد الرقيب يوسف من لفة رأس الملك الملفوفة حول قلنسوته المخروطية، انه ملك من ملوك الدولة الفرثية الآرية التي حكمت في شمال

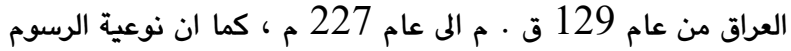
والرموز والنحت التي وجدت، ريما من عهد تلك الدولة ، ولا يستبعد ان يكون مشيده فرهاد الثاني، الذي قضى على الدولة السلوقية في كوردستان وايران وسحق عام 129 ق • م جيش انطيوخوس السابع الذي كان قوامه ثلاثمائة ألف، وذلك في منطقة عقرة (54) وفي عام 2004 كلفت دائرة اشغال دهوك مقاولاً بترميم الجسر خلال 80 يوماً ، لكن العمل أوقف من قبل رئاسة مجلس الوزراء في اقليم كوردستان، بسبب التحفظ الذي أبداه عبد الرقيب يوسف وعدد من الإثاريين في دهوك، على اعتبار ان ترميمه يجب أن يتم تحت اشراف خبراء متخصصين في الاثار من عرب وكرد واجانب لمدة لا تقل عن سنتين، مع حل الكتابات البهلوية، واتفق الجميع في النهاية على أن أن يكون التنفيذ من قبل وزارة الثقافة في الإقليم، وتم تكليف مدير آثار

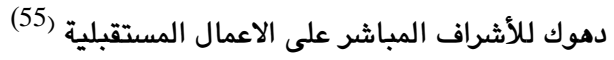

\section{6. استناجات البحث:}

1- رغم كل ما قيل وكتب بشأن تاريخ أنشاء الجسر، يبقى باب الجدل في ذلك مفتوحاً الى يومنا هذا، بسبب الغموض الذي ينتاب الحقبة

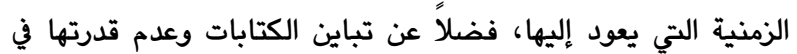
الوصول الى الحقيقية النهائية. 2- صمود الجسر ومقاومته للظروف الطبيعية حتى الوقت الحاضر،

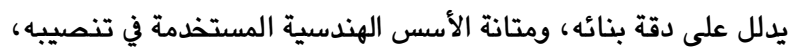
ناهيك عن أسلوب رفع الأقواس التي تحمله مع تثبيتها ببراعة تامة ، الأمر الذي يعطي انطباعاً عن فن العمارة وتطورها في عصر تشييده. 3-موقع الجسر على نهر الخابور، يؤكد الأهمية الاقتصادي لزاخو فئوسي كمعبر تجاري شاع استخدامه على نطاق واسع في القرون الوسطى، لنقل

البضائع وتبادلها بين العراق وايران وارمينيا وديار بكر. 4- أما فيما يتعلق بالتنقيبات الآثارية التي اجريت عليه، فلا زالت

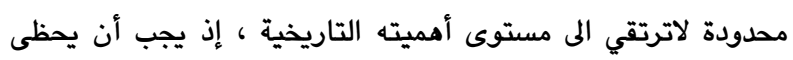
بمزيد من الدعم والرعاية.

\section{7. الهوامش والتعليقات:}

(1) ميخائيل عواد، الجسر العباسي، الرسالة (مجلة)، القاهرة، العدد

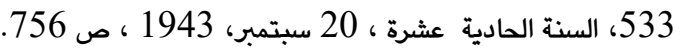

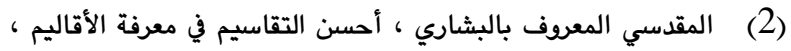

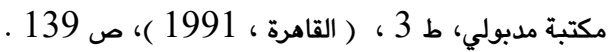

وقبل أن يكتمل البناء توفى الأمير حسن العباسي، ليخلفه في الحكم ابنه الأمير سلطان حسين العباسي الذي قدر له الاستمرار في المشروع حتى النهاية (46) . اما لماذا لم تظهر كتابات تؤرخ بناء الجسر على ايدي البهدينانيين؟ فالجواب حسب وجهة نظر خضر العباسي، ان العثمانيين سعوا في القضاء على الامارة البهدينانية ، وازالتها من عالم الوجود ، لذلك فقد خشي أمرائها ان يتظاهروا علنا بالكتابة باسم الاسرة العباسية التي ينتمون لها (47). ومكذا اخذت بعض الأوساط المختصة في مديرية الآثار العامة في العراق بمعتقد خضر العباسي ، وأرجعت بناء الجسر الى الامارة البهدينانية، على اعتبار أن زمن تشييده لا يمكن ان يرقى الى أكثر من أريعمائة عام

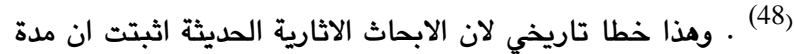
وتاريخ بناء الجسر يعود لعصور تاريخية قبل ظهور الاسلام .

\section{5. التنقيبات الاثارية وأعمال الصيانة في جسر زاخو}

صنف جسر زاخو من بين المواقع الاثرية العديدة المسجلة والمعلن عن اثريتها في العراق(49) ، بموجب جريدة الوقائع العراقية ذي العدد)

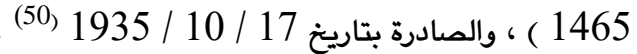
ويناءً على تلك المعطيات تم اجراء الكشف على الجسر عام 1942 لغرض الاعداد لأعمال الصيانة فيه، والتي بدأت مراحلها الأولى عام 1955 ، ولكن على نطاق ضيق ـ ثم توسع العمل بعد ذلك بسنوات،

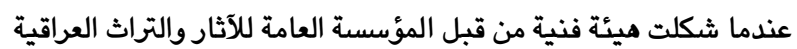
بموجب الأمر المرقم (9289) والمؤرخ في 1977/7/3 برئاسة جرجيس محمد فاضل ، وعضوية فاضل عباس (51) ، وقد تركز نشاطها الذي بدأ بعد سبعة أيام من التاريخ المشار إليه في اعادة بناء

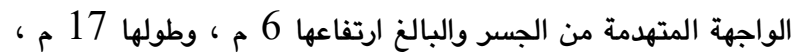
وينفس القياسات السابقة للأحجار المستعملة في تشييده ، ثم تم بناء الجزء المتهدم منه بطول 20 م ، وارتفاع 30 سم ، وسمك 40 سم ، كما تم ملء ما بين حافات الطابوق بمادة السمنت في الواجهة الغربية ، والمحصورة بين الجزء المتهدم من جهة، والقوس الكبير من جهة أخرى ، وكذلك الأجزاء المتصدعة من باطن القوس المتوسط ، والواجهة الشرقية للجسر، من بدايته حتى بداية القوس الكبير، فضلاً عن الواجهة

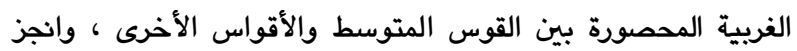
العمل بشكل نهائي في 1977/10/16 (52) وفي عام 2005 كثف لنا الاثاري المعروف عبد الرقيب يوسف عن حقيقة جديدة كانت مغيبة لقرون عدة على الاثاريين والمؤرخين والرحالة والمستشرقين ، مفادها انه تمكن من الوصول الى مجموعة من الصور

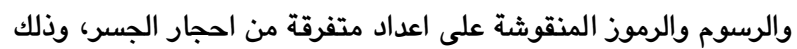
بعد سلسلة من اعمال التنقيب التي أجراها بنفسه خلال الأريع سنوات التي تلت عام 2000 ، منها صورة الملك الذي شيد الجسر، وصورة 
(24) ميخائيل عواد ، المصدر السابق ، ص 757 .

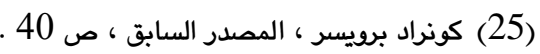

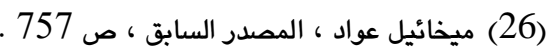

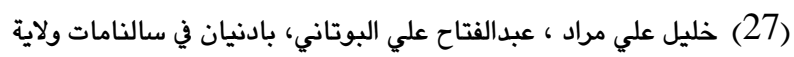

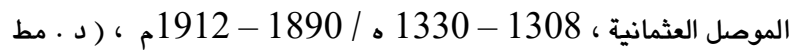

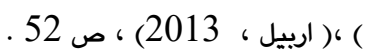

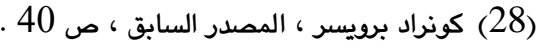

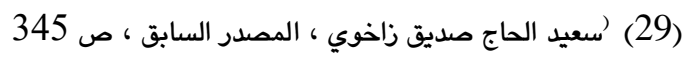

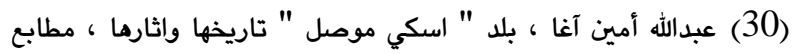

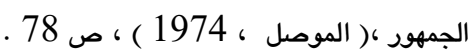

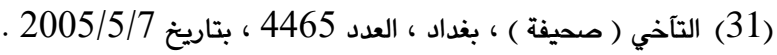

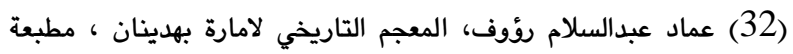

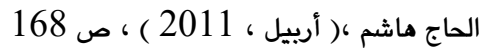

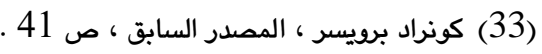

(34) المقدسي المعروف بالبشاري ، المصدر السابق ، ص ص 139 ـ 139 .

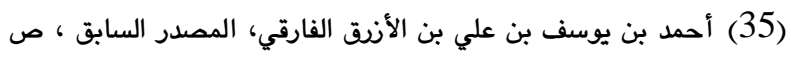

(36) عبد الرقيب يوسف ، الدولة الدوستكية في كردستان الوسطى ، ج 26324 ، (37) كان هؤلاء يقاتلون بمعية حاكم أسيا الصغرى الأمير كورش الأصغر

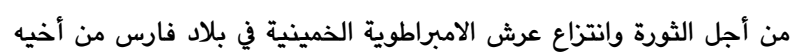

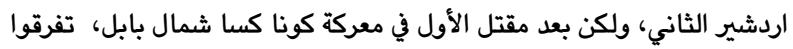

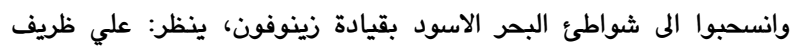

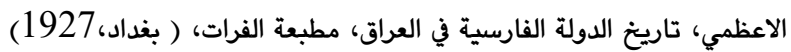

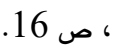
(38) جمال الدين بابان، اصول اسماء المدن والمواقع العراقية ، (د . مط

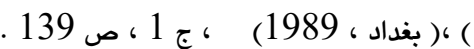

(39) (1) F.R.G.S, William F . Ainsworth , F.G.S,Travels in the Track of the Ten Thousand Greeks , London , 1996 , p . 144 ;

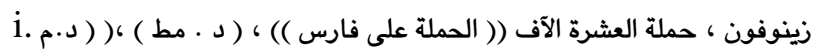

. ().د) ( ) ( )

(40) محفوظ العباسي، امارة بهدينان العباسية ، مطبعة الجمهورية ، (د) ) ( الموصل ، 1969 )، ص ص 113 ) 113

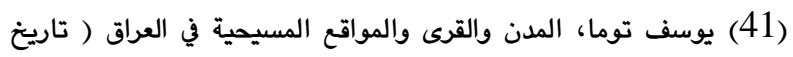
وجغرافية ) ، تقديم : فؤاد يوسف قزانجي ، ( د . مط ) ، بغداد ، 2013 ) )

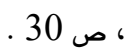

(42) (马) Hammerton ,Sir, J.A., Wonders of the Past, London, N.D, Vol.III, P,1130.

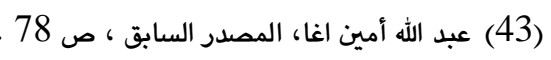

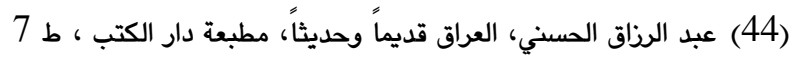

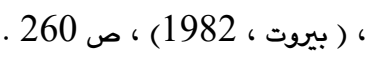

$$
\begin{aligned}
& \text { (45) خضر العباسي، المصدر السابق ، ص بروت ، } 16 \text { ، } 16
\end{aligned}
$$

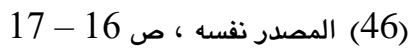

(3) نصر الدولة أحمد بن مروان كل: ملك من ملوك الدولة المروانية في ديار بكر، أتفق المؤرخون على أنه ملكاً يتحدث بعظمة الكبار، وتضرب مندوله مندله وحزمه الامثال، وهو أشهر الحكام المروانيين، وقد اشتهر بلقب العادل، ينظر:

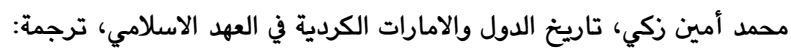

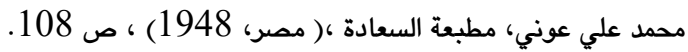

(4) أحمد بن يوسف بن علي بن الأزق الفارقي، تاريخ الفارقي، تحقيق،

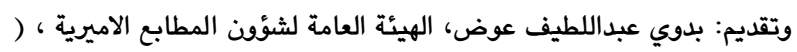

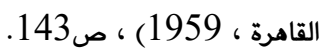

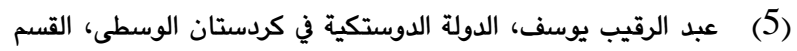

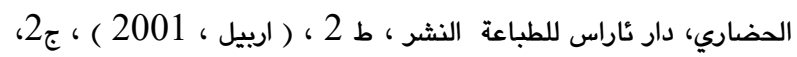

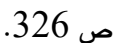

(6) العر العباسي، تاريخ بلدة زاخو والجسر العباسي صفحة مجهولة من

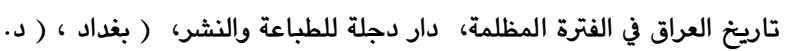

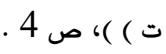
(7) ( ) بهاب الدين أبي عبدالله ياقوت بن عبدالله الحموي الرومي البغدادي ، دار احياء التراث العربي للطباعة والنشر والتوزيع ، ( بيروت ، 2008 ، 200 ) )

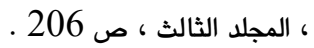
(8) سعيد الحاج صديق زاخوي ، زاخو الماضي والحاضر، مراجعة وتقديم

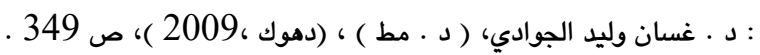

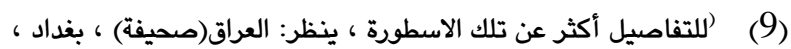

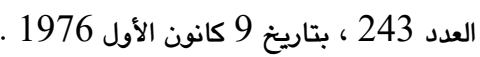
(10) (خالد محمد شريف السندي ، زاخو وامارة سنديان ، مطبعة المسرة

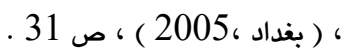

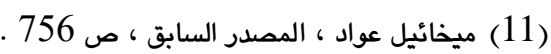

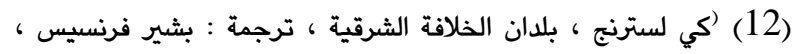

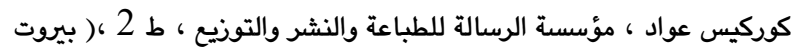
123 - 1985) ، كو 122

(13) ${ }^{(1)}$ Lowthian Bell, Gertrude , A murath to A murath , London , 1911 , p . 287

(14) ${ }^{(1)}$ Anonymous , From Monte to Mousl, London, 1909 , p.135 - 136 .

(15) عبد الرقيب يوسف، جسر زاخو الأثري ، بين النهرين(مجلة) ، العدد المد ،

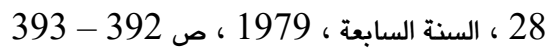

$$
\begin{aligned}
& \text { (16) ميخائيل عواد ، المصدر السابق ، ص } 28 \text { ، } 756 \text { ، } 757 \text { ، }
\end{aligned}
$$

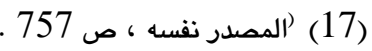

(18) (طه باقر ، فؤاد سفر ، المرشد الى مواطن الاثار والحضارة الرحلة

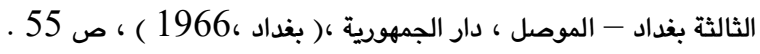

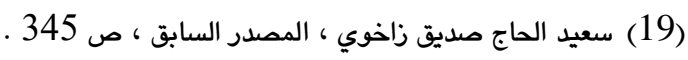

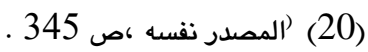

(21) كونراد برويسر، المباني الأثرية في شمال بلاد الرافدين في العصور

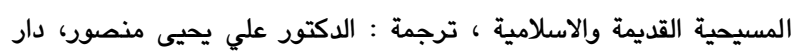

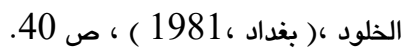

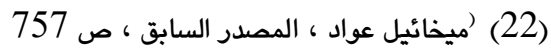

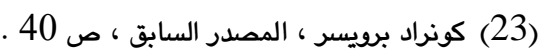


شهاب الدين أبي عبدالله ياقوت بن عبدالله الحموي الرومي البغدادي ،

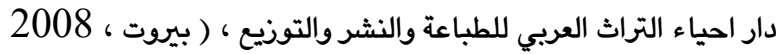
)، المجلد الثالث.

طه باقر ، فؤاد سفر ، المرثد الى مواطن الاثار والحضارة الرحلة

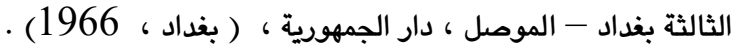

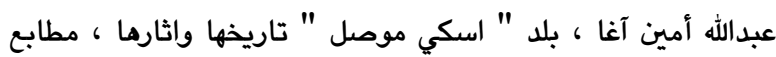
الجمهور، ( الموصل ، 1974).

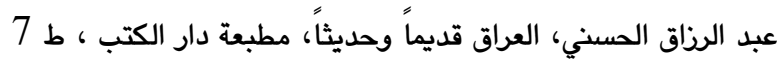

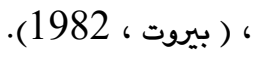

عبد الرقيب يوسف، الدولة الدوستكية في كردستان الوسطى، القسم

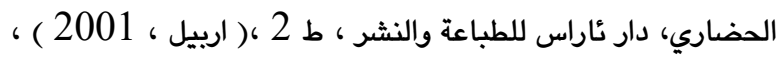
ع.

علي ظريف الاعظمي، تاريخ الدولة الفارسية في العراق ، مطبعة الفرات،

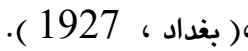

عماد عبدالسلام رؤوف، المعجم التاريخي لامارة بهدينان ، مطبعة

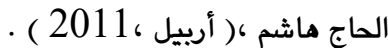
قحطان رثيد صالح، الكشاف الاثري في العراق، الموصل، جامعة الموصل، مديرية دار الكتب للطباعة والنشر، ( الموصل ، 1987). كونراد برويسر، المباني الأثرية في شمال بلاد الرافدين في العصور المسيحية القديمة والاسلامية ، ترجمة : الدكتور علي يحيى منصور ، دار الخلود ، (بغداد ، 1981 ) ).

كي لسترنج ، بلدان الخلافة الشرقية ، ترجمة : بشير فرنسيس ،

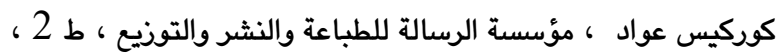

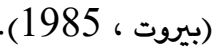

محفوظ العباسي، امارة بهدينان العباسية ، مطبعة الجمهورية، (10ة)

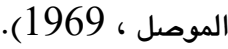
محمد أمين زكي، تاريخ الدول والامارات الكردية في العهد الاسلامي، ترجمة: محمد علي عوني، مطبعة السعادة، (مصر ، 1948 ) ). المقدسي المعروف بالبشاري ، أحسن التقاسيم في معرفة الأقاليم ، مكتبة مدبولي، ط 3،( القاهرة ، 1991). يوسف توما، المدن والقرى والمواقع المسيحية في العراق ( تاريخ وجغرافية ) ، تقديم : فؤاد يوسف قزانجي ، ( د . مط ) ، ( بغداد ،

\section{8 المصادر باللغة الانكليزية:}

1- Anonymous, From Monte to Mousl, London , 1909.

2- F.R.G.S, William F . Ainsworth , F.G.S,Travels in the Track of the Ten Thousand Greeks , London , 1996.

3- Hammerton ,Sir, J.A., Wonders of the Past, London, N.D, Vol.III.
(47) المصدر نفسه ، ص 19 (48)

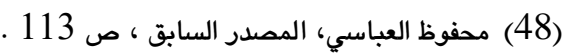

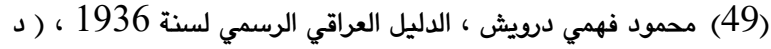

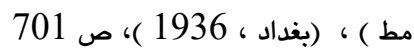
(50) الوقائع العراقية( صحيفة) ، بغداد ، العدد 1465 ، بتاريخ 1935/10/17 (51) ينظر: المؤسسة العام للآثار والتراث، مركز التوثيق، القطاع: جسور / دهوك، النوع : تنقيب ، الموقع : الجسر العباسي في زاخو، رقم الوثيقة 2 / 2 / ه ت ، التاريخ 1977 ، ورقة 2 و و 3 . 3.

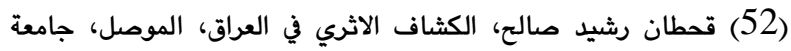

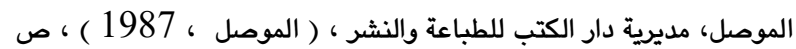

(53) (التآخي(صحيفة) ، بغداد ، العدد 4465 ، بتاريخ 2005/5/7 . (55) المصدر نفسه .

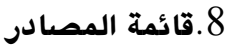

1.8 الوثائق الغير منشورة والمنشورة:

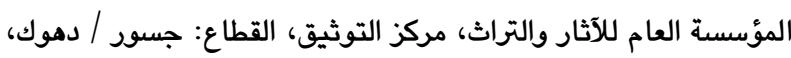
النوع : تنقيب ، الموقع : الجسر العباسي في زاخو، رقم الوثيقة 2 / هـ

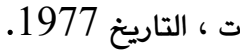
محمود فهمي درويش ، الدليل العراقي الرسمي لسنة 1936 ، بغداد ،

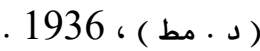

2.8 المصادر والمراجع العربية والمعربة: أحمد بن يوسف بن علي بن الأنرق الفارقي، تاريخ الفارقي، تحقيق وتقديم: بدوي عبد اللطيف عوض، الهيئة العامة لشؤون المطابع

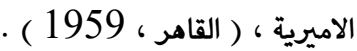

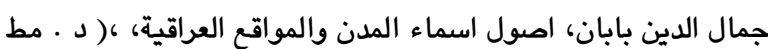

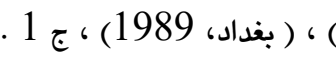

خالد محمد شريف السندي ، زاخو وامارة سنديان ، مطبعة المسرة ،

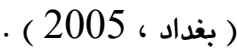

خضر العباسي، تاريخ بلدة زاخو والجسر العباسي صفحة مجهولة من تاريخ العراق في الفترة المظلمة ، دار دجلة للطباعة والنشر، ( بغداد ، $\cdot(()$ ) ( ) ( ) ( ) خليل علي مراد ، عبدالفتاح علي البوتاني، بادنيان في سالنامات ولاية

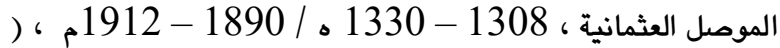

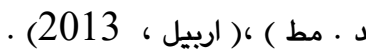
زينوفون ، حملة العشرة الآف (( الحملة على فارس )) ، ( د . مط )

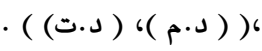

سعيد الحاج صديق زاخوي ، زاخو الماضي والحاضر، مراجعة وتقديم : د. . غسان وليد الجوادي ،( د. مط )، ( دهوك ، 2009) . 
5.8 الصحف

1 التآخي ( صحيفة ) ، بغداد ، العدد 4465 ، بتاريخ .2005/5/7

2- العراق(صحيفة) ، بغداد ، العدد 243 ، بتاريخ 9 كانون الأول

.1976

3- الوقائع العراقية( صحيفة) ، بغداد ، العدد 1465 ، بتاريخ 1935/10/17
4- Lowthian Bell, Gertrude, A murath to A murath , London , 1911.

$$
4.8 \text { البحوث والدراسات المنشورة: }
$$

1-عبد الرقيب يوسف، جسر زاخو الأثري ، بين النهرين(مجلة) ، العدد 28 ، السنة السابعة ، 1979.

2- ميخائيل عواد، الجسر العباسي، الرسالة (مجلة)، القاهرة ، العدد ، العداد

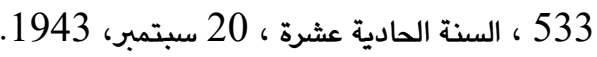




\title{
يرا زاخوّ يا شوينوارى د يُولينكرنيّن عهرهبى و رِّزَئاثاييدا
}

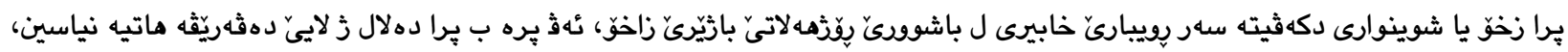

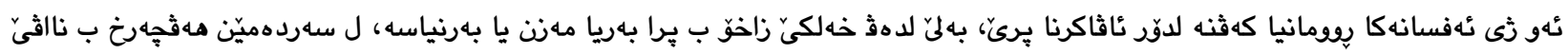

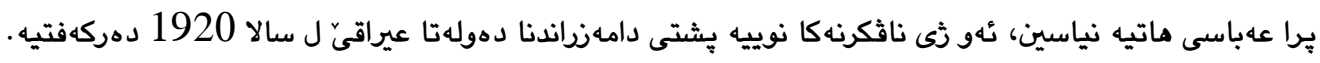

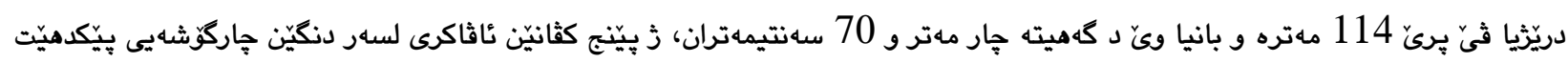

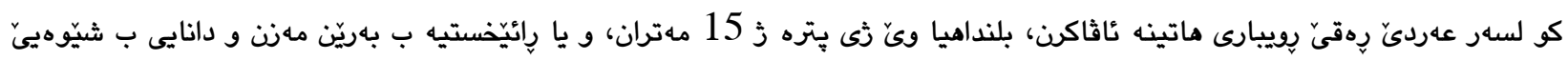

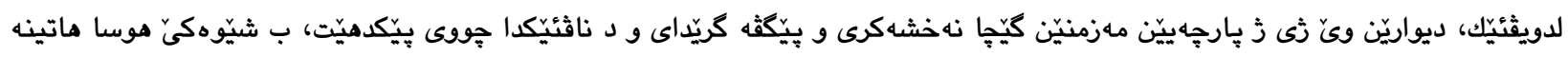

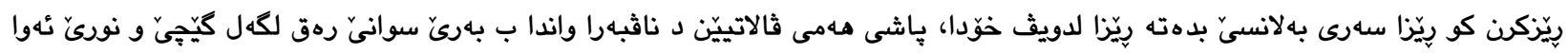

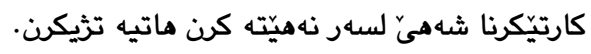

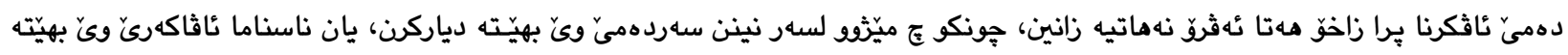

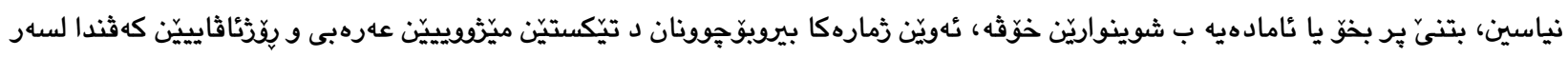

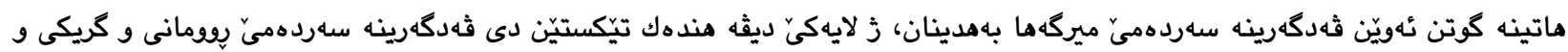

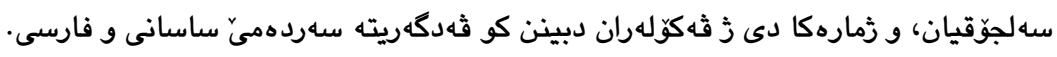

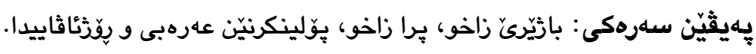

\section{ZAKHO ANCIENT BRIDGE IN ARABIC AND WESTERN HISTORICAL SOURCES}

\begin{abstract}
Zakho Ancient Bridge spans Al-Khaboor River at the south-eastern side of current city of Zakho. It has been known in the region as Dalali Bridge, after a Roman legend related to its construction, but it is known to Zakho residents as the Great Masonic Bridge. In modern ages, it has been known as the Abbasid Bridge, a new name that appeared after the establishment of the Iraqi State in 1920. The bridge spans for 114 meters, and its width is 4,70 meters. It consists of five parts relying on square, large pillars built on the river solid land. The distance between its top and the river bed is more than 15 meters. It is paved with large pieces of stone laid in in a gradient manner. It walls were made from large pieces of lime stones, put very close to each other and intertwining with each other. The stones were ordered in a manner that makes each row keep the balance of the row below it. All of the Bridge middle holes were filled with hard flint stone with lime and mortar that is resistant to humidity.

The date on which Zakho Bridge was built is unknown. It contains no stone stating such date or even giving the identity of the builders. All what is there is the bridge itself. Ancient Arabic and westerns sources contain many conjectures about its construction actual date. Some dated the Bridge back to Bahdinan Principality Era; some to Roman, Greek, or Seleucid State; while others dated it back to the Sassanid and Persian era.
\end{abstract}

Keywords: Zakho city, Zakho bridge, Arabic and Western Historical Sources. 